\title{
DATA MINING AND ITS IMPACT ON MARKETING COMMUNICATION - CASE: HEAT-TREATED BIRCH WOOD
}

\author{
Roman Dudík, Vlastimil Borůvka, Marcel Riedl, Tomáš Holeček \\ Czech University Of Life Sciences Prague \\ Czech Republic
}

(Received September 2020)

\begin{abstract}
The article presents the results of a marketing survey in the area of customer preferences in the case of different degrees of heat-treated solid wood and birch veneer. Part of the marketing survey was a questionnaire survey, where the respondents, as potential customers, expressed their preferences for individual samples which, at first glance, differed in colour due to the different degrees of heat treatment. The result of the research is a clear preference for the heat-treated samples compared to the reference sample without heat treatment. A more detailed secondary analysis of the data from the questionnaire survey was performed with regard to the gender, age and education of the respondents. Here, too, it is possible to conclude a clear preference for heat-treated samples for these groups of respondents. The article also analyses the possibilities of the marketing strategy with a focus on marketing communication, especially in relation to wood processors and producers.
\end{abstract}

KEYWORDS: Birch, attractiveness, marketing analysis, questionnaire survey, consumer preferences, heat treatment. 


\section{INTRODUCTION}

This article builds on the published research results (Borůvka et al. 2019) in the field of investigating the properties of Betula pendula wood (Silver birch), which were concluded by marketing analysis (Dudík et al. 2020). The reason for the marketing investigation and the subsequent initial marketing analysis was to determine whether there is the potential for customer interest in heat-treated birch wood. The identified interest of customers can then create a precondition for the greater use of such wood, for example in the furniture industry. A secondary data analysis is also performed, which also relates to a deeper examination of the potential interest of customers in heat-treated birch wood. The article presents unpublished results resulting from this secondary analysis of marketing survey data.

According to Espinoza (2015), the existing literature shows that the technical aspects of the thermal modification of wood have received considerable attention in the past; however, only limited attention has been paid to the market opportunities of thermally modified wood-based products.Accordingly, Militzand Lande(2009) statesthatmodifiedwoodsareunknown to the market, and it will take time and effort to educate the market players about the advantages of such new materials. Recently, developer modified woods lack this history and, therefore, many properties that the market normally takes for granted need to be explained when marketing a new material.

For these reasons, this article newly presents the theoretical basis for the communication of these findings both in relation to the end customers (consumers) and especially in relation to professional customers, i.e., processors and furniture companies. As stated by Gamache (2017), thermally modified wood (TMW) has multiple applications and offers an opportunity for high value-added uses for timber resources that are underutilised or affected by invasive species, which can improve the forest health and create economic opportunities in rural communities. This argument is also related to the changing position of birch as a tree in the Czech Republic. The position of birch as a woody plant purposefully grown in the Czech Republic until its felling age has been published before, and there is an obvious shift in the view of the importance of birch from a weed wood to an economically important one in the future (Dudík 2018). Information on the position of birch in the wood processing industry of the Czech Republic has also been described by Borůvka et al. (2019).

As part of the secondary analysis, the article evaluates the extent to which the colour changes of the heat-treated solid wood and birch veneer are interesting for individual customer groups from a marketing point of view. An economic evaluation of the production and processing of heat-treated wood and birch veneers is not solved here. The reason for the secondary analysis is to obtain an initial finding whether it makes any sense from the point of view of individual customer groups to consider the importance and use of colour changes in birch wood. This sequence of steps corresponds to a concept testing phase in the development of a new product and is the starting point for a marketing and business analysis. This then facilitates the successful commercialisation associated with the marketing of the product. Because the demand for wood is a driven demand depending on the situation in other industries, that use wood as a raw material, the development of value added in the wood processing industry might be affected also by situation in these industries (Palátová 2019).

According to Bhuiyan (2011), most decisions about launching new products are preceded by marketing research. In our case, the opinion of customers was ascertained by a questionnaire survey. The aim of the survey was to determine the degree of attractiveness of heat-treated samples of solid wood and veneers for potential customers with regard to their perception in the colour differences of the samples and their related preferences. The sample of respondents was sufficient 
for the analysis of the responses using statistical methods and to determine whether it is possible to apply the results of the questionnaire survey to the entire population - this was confirmed by (Dudík et al. 2020). In addition, it should be mentioned that the testing should not be solely restricted to this stage; it must be conducted throughout the new product development process (Ulrich and Eppinger 2007) as stated by Cooper (2019) in building the "voice-of-customer".

Work has previously been published that states that the heat treatment of wood gives it, among other things, an attractive colour, which is important from an aesthetic point of view (Santos et al. 2014, Sedlar et al. 2019, Cademartori et al. 2014). The positive importance of darker wood colours in relation to market preferences is reported by Zanuttini et al. (2020). Thus, a dark colour can give the wood a feeling of higher value in some countries and, from this point of view, can be an important benefit of heat treatment. It follows that the heat treatment of wood can increase the market acceptance of such wood (Jirouš-Rajković and Miklečić 2019). In Czech conditions, the heat treatment of birch wood can be considered an innovation in the processing of the birch wood raw material. According to Loucanova et al. (2017), innovation is an important prerequisite for commercial success in the market. From a macroeconomics point of view, this has a positive impact on the consumption, which is a key driver of an economy (Parobek and Palus 2008). Consumption is influenced by the preferences of the customers' decision-making factors, which also applies to purchasing furniture. The most relevant factors affecting the purchasing decision are the quality, price and design of the furniture (Kaputa and Supín 2010. The design is then closely linked to the perception of the furniture's colours by the customers.

\section{MATERIAL AND METHODS}

\section{Marketing investigation}

The starting point for the analysis of the influence of the colour shade of the solid birch wood and birch veneer on the decisions of potential customers is a questionnaire survey on a random sample of 102 people from the population of the Czech Republic. The attractiveness of the colour appearance of real samples of solid birch wood ( 1 reference sample and 5 samples with different degrees of thermal treatment) and birch veneer ( 1 reference sample and 4 samples with different degrees of thermal treatment) was analysed. For the solid wood samples, Roman numerals I to VI were used, with the reference sample being I. For the veneer samples, letters of the alphabet $\mathrm{A}$ to $\mathrm{E}$ were used, with the reference sample being $\mathrm{A}$. The methodology of the production and heat treatment of solid wood and birch veneer samples has been published in the article by Borůvka et al. (2019) and Dudík et al. (2020), where the colour representation of the samples is also given.

The designation and characteristics of the samples:

I. Solid wood - untreated (BR-SW-REF) - the lightest colour shade

II. Solid wood - treated at $160^{\circ} \mathrm{C} / 3 \mathrm{~h}$ (BR-SW-160-3)

III. Solid wood - treated at $170^{\circ} \mathrm{C} / 3 \mathrm{~h}$ (BR-SW-170-3)

IV. Solid wood - treated at $180^{\circ} \mathrm{C} / 3 \mathrm{~h}$ (BR-SW-180-3)

V. Solid wood - treated at $190^{\circ} \mathrm{C} / 3 \mathrm{~h}$ (BR-SW-190-3)

VI. Solid wood - treated at $200^{\circ} \mathrm{C} / 3 \mathrm{~h}$ (BR-SW-200-3) - the darkest colour shade

A. Veneer - untreated (BR-REF) - the lightest colour shade

B. Veneer - treated at $170^{\circ} \mathrm{C} / 3 \mathrm{~h}(\mathrm{BR}-170-3)$ 
C. Veneer - treated at $190^{\circ} \mathrm{C} / 3 \mathrm{~h}(\mathrm{BR}-190-3)$

D. Veneer - treated at $190^{\circ} \mathrm{C} / 5 \mathrm{~h}(\mathrm{BR}-190-5)$

E. Veneer - treated at $200^{\circ} \mathrm{C} / 3 \mathrm{~h}(\mathrm{BR}-200-3)$ - the darkest colour shade.

Aware of the possible subconscious influence of the environment in which the respondents live in on their preferences, the attractiveness of the colour appearance of the samples was examined in two variants. The first variant concerned the determination of the attractiveness of the coloured samples of solid wood and veneer during the first furnishing of a new house / flat with furniture (e.g., living room). The second variant was the purchase of a piece of furniture (e.g., in the living room) to the already existing equipment of the house / flat. The level of attractiveness of each individual sample of the solid wood and birch veneer was also very important information, which was evaluated according to the selected point scale ( 1 point - the least preferable, 5 points - the greatest preference). In other words, the emotional degree of the attractiveness of individual samples was determined. In addition, the gender, age and educational level of each respondent were surveyed. The full text of the questionnaire is published in the article by Dudík et al. (2020).

The data obtained by the questionnaire survey were processed in the first phase by graphical methods of descriptive statistics. The statistical significance of the differences in the preference between the different groups of respondents was evaluated using the Chi-square Goodness of the Fit Test. The estimation of the proportion of the people in the population preferring the thermal wood treatment was made as an interval estimate of the p-binomial distribution parameter (Wonnacot and Wonnacot 1977), i.e

$$
P\left[\frac{x}{n}-u(\alpha / 2) \sqrt{\frac{x / n(1-x / n)}{n}}<p<\frac{x}{n}+u(\alpha / 2) \sqrt{\frac{x / n(1-x / n)}{n}}\right]=1-\alpha
$$

The statistical evaluation of the questionnaire survey was performed in the program R Version 3.6.1. (The R Foundation, Austria). The same significance level ( $\alpha=0.05)$ was used for the analyses (Dudík et al. 2020).

\section{Marketing strategy}

In the case of a new technology, Lane (1999) distinguishes between two basic approaches (Fig. 1).

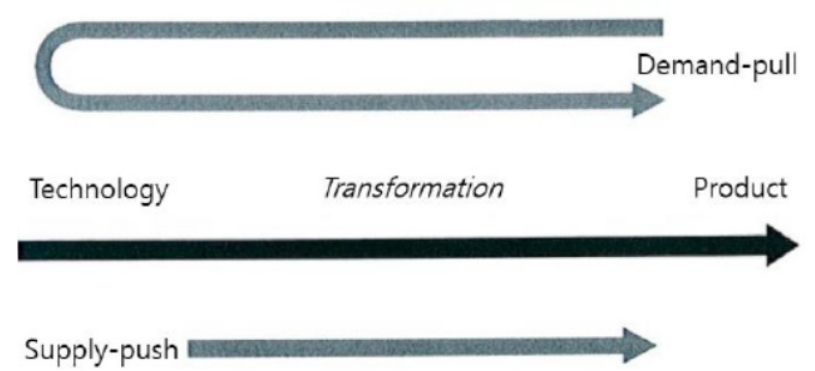

Fig. 1: The push and pull forces initiate the technology transfer (Lane 1999).

In our case, it is a supply-push, where the researchers who used a technology that is not 
used in the Czech Republic, in the case of the birch wood, to initiate the technology transfer process (from the left side of Fig. 1) by creating pressure on the use of these innovative technologies by entities that can apply these technologies in products (e.g., wood processing companies, furniture manufacturers, etc.). The market opportunity arises from the fact that the technology supplied demonstrates a feasible solution to an existing problem, or because the desired product demonstrates commercial viability. From the results below, it is clear that from the consumer's point of view, the product, as a material, is sufficiently attractive due to the fact that this technology allows sufficient colour variability based on the fashion and customer requirements. At this stage, it is, therefore, necessary to focus the supply-push marketing strategy on the communication on the relevant links in the value chain. In his article, Choe (2019) analyses the factors influencing the technology transfer performance and presents a more detailed classification of these strategies - in our case, it is a target push (Fig. 2).

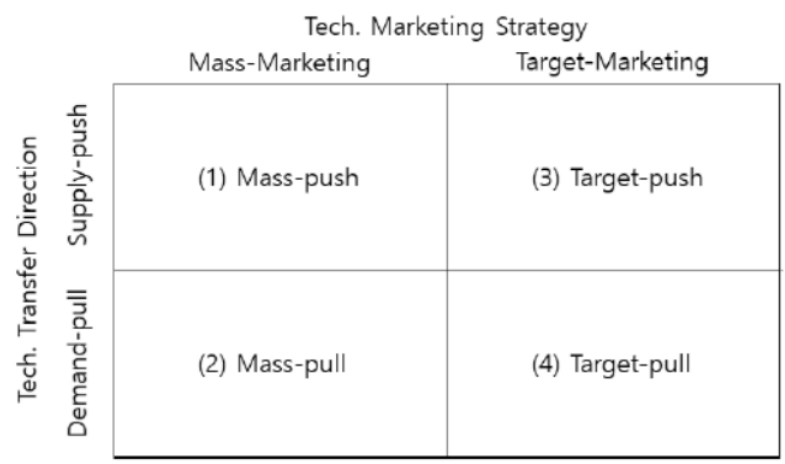

Fig. 2: Research framework: Types of technology transfer (Choe 2019).

One of the main starting points for further managerial decision-making in this area and the implementation of this strategy is a processed SWOT analysis. Details concerning the quality processing of the SWOT analysis of its versatile use are given, for example, by Benzaghta (2021). The processed SWOT analysis and the possibilities of its application are presented at the end of the following chapter.

\section{RESULTS AND DISCUSSION}

\section{Initial analysis}

The results of the initial analysis of the information obtained from the questionnaire survey (Dudík et al. 2020) show a clear predominant share of potential customers who prefer a variant of heat-treated wood or birch veneer. The share of respondents willing to buy furniture made of wood or birch veneer with thermal treatment is between 0.824 and 0.912 . For the calculation of the intervals, a level of significance was chosen at $\alpha=0.05$, i.e., the resulting intervals cover the actual share of people interested in furniture with a thermal treatment with a probability of 0.95 . None of the intervals contains the number 0 , so we can reject (at a significance level of 0.05) the hypothesis of zero interest of people in the Czech Republic in furniture with thermally treated wood. In addition, none of the intervals contains a number of 0.5 or less, so it can be estimated that the share of these people in the population is more than half. 
The results of the sample preferences, in the case of purchasing a supplemental piece of furniture and new home furnishings, for solid wood and birch veneer samples have already been published (Dudík et al. 2020). The samples of solid birch wood without heat treatment (BR-SW-REF), namely at the level of approx. 9\% in the case of new flat furnishing and approx. $11 \%$ in the case of purchasing a supplemental piece of furniture, obviously achieved a low preference level. Similarly, the low preference level of birch veneer samples without heat treatment (BR-REF) is evident, at the level of approx. $18 \%$ in the case of new flat furnishings and in the case of purchasing a supplemental piece of furniture.

\section{Secondary analysis of the marketing research}

As part of the secondary analysis of the data obtained from the questionnaire survey, the structure of information on customer preferences was examined in more detail in terms of gender (men, women), age (younger: under 30, older: 31 and older) and education (up to secondary, university and higher). Tab. 1 shows the proportions of the respondents by gender willing to purchase wooden furniture with a thermal treatment.

Tab. 1: Proportions of respondents by gender willing to purchase wooden furniture with a thermal treatment.

\begin{tabular}{|c|c|c|c|c|}
\hline \multirow{2}{*}{ Type of purchase } & Type of furniture & Gender & $\begin{array}{c}\text { Proportion of } \\
\text { respondents }\end{array}$ & $\begin{array}{c}\text { Interval estimate } \\
\text { of the share in the } \\
\text { population }\end{array}$ \\
\hline \multirow{3}{*}{ Furnishing a new flat } & \multirow{2}{*}{ Solid wood } & Female & 0.971 & $0.914-1.000$ \\
\cline { 3 - 5 } & \multirow{2}{*}{ Veneer } & Male & 0.882 & $0.806-0.959$ \\
\cline { 3 - 5 } & \multirow{2}{*}{$\begin{array}{l}\text { Purchasing a } \\
\text { supplemental piece of } \\
\text { furniture }\end{array}$} & Female & 0.824 & $0.695-0.952$ \\
\cline { 2 - 5 } & \multirow{2}{*}{ Veneer } & Male & 0.824 & $0.733-0.914$ \\
\cline { 3 - 5 } & & Female & 0.882 & $0.774-0.991$ \\
\cline { 2 - 5 } & Male & 0.897 & $0.825-0.969$ \\
\hline
\end{tabular}

For the solid wood furniture for new flat furnishings, we can observe significant differences between men and women. The achieved level of significance is 0.006 . Women obviously prefer light shades. The exception is the darkest shade, which is also popular with women (Fig. 3).

In the case of purchasing a supplemental piece of solid wood furniture, the interest in different shades is balanced (Fig. 3). The achieved level of significance is 0.912 .

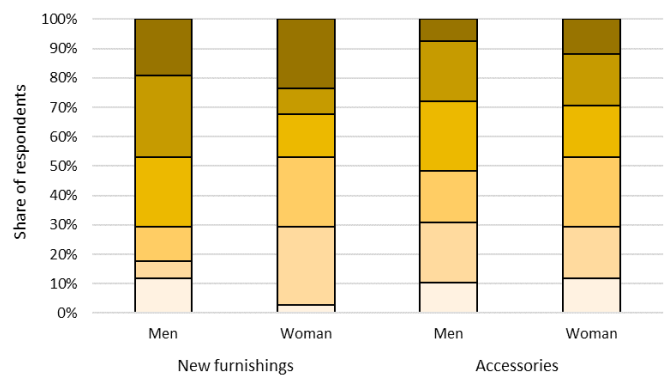

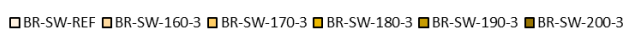

Fig. 3: New flat furnishing and purchasing a solid wood furniture accessory - the differences between women and men. 
We did not observe any significant differences between men and women for the new flat furnishings made from veneer. The achieved level of significance is 0.213 . Men have the largest share of preferences for the medium colour shade (Fig. 4). In the case of complementary piece of veneer furniture, the interest in different shades is rather balanced (Fig. 4). Again, we did not observe any significant differences. Men, again, have the largest share of preferences for the medium colour shade. The achieved level of significance is 0.140 .

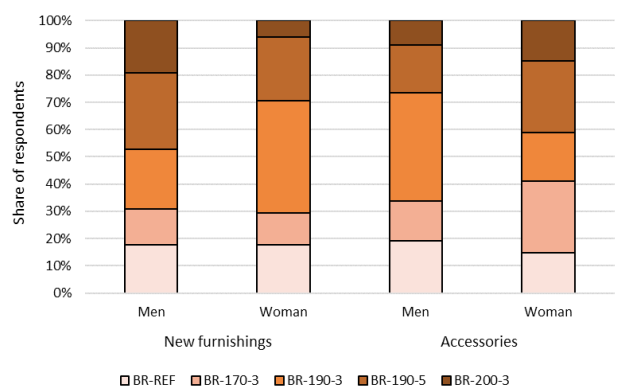

Fig. 4: New flat furnishings and purchasing furniture accessories from veneer-differences between the women and men.

The structure of information on the customer preferences in terms of their age (younger: up to 30 years, older: 31 and more years) is shown in Tab. 2 .

Tab. 2: Proportions of respondents according to their age willing to buy wood furniture with a thermal treatment.

\begin{tabular}{|c|c|c|c|c|}
\hline Type of purchase & Type of furniture & Age & $\begin{array}{c}\text { Proportion } \\
\text { of respondents }\end{array}$ & $\begin{array}{c}\text { Interval estimate } \\
\text { of the share in the } \\
\text { population }\end{array}$ \\
\hline \multirow{4}{*}{ Furnishing a new flat } & \multirow{2}{*}{ Solid wood } & Younger & 0.913 & $0.847-0.978$ \\
\hline & & Older & 0.909 & $0.811-1.000$ \\
\hline & \multirow{2}{*}{ Veneer } & Younger & 0.841 & $0.754-0.927$ \\
\hline & & Older & 0.788 & $0.648-0.927$ \\
\hline \multirow{4}{*}{$\begin{array}{l}\text { Purchasing } \\
\text { a supplemental piece } \\
\text { of furniture }\end{array}$} & \multirow{2}{*}{ Solid wood } & Younger & 0.870 & $0.790-0.949$ \\
\hline & & Older & 0.939 & $0.858-1.000$ \\
\hline & \multirow{2}{*}{ Veneer } & Younger & 0.797 & $0.702-0.892$ \\
\hline & & Older & 0.879 & $0.767-0.990$ \\
\hline
\end{tabular}

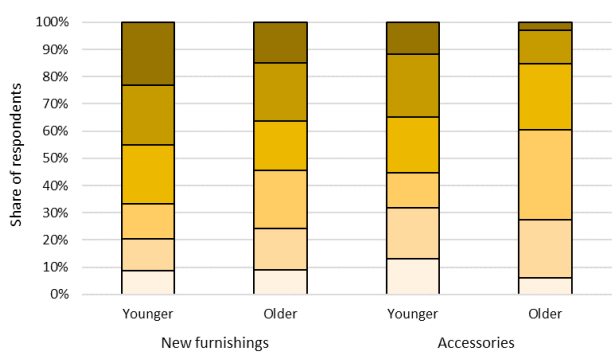

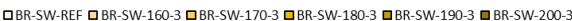

Fig. 5: New flat furnishings and purchasing a solid wood furniture accessory - differences between the age groups. 
We did not observe any significant differences between the age groups for veneer furniture for the new flat furnishings. The achieved level of significance is 0.778 . The medium dark shade has the largest preference in the older age group (Fig. 6).

In the case of complementary veneer furniture, the interest in the different shades is less balanced (Fig. 6). Nevertheless, the differences between the age groups are not statistically significant. The achieved level of significance is 0.106. Again, the medium dark shade (BR-190-3) has the largest preference in the younger age group.

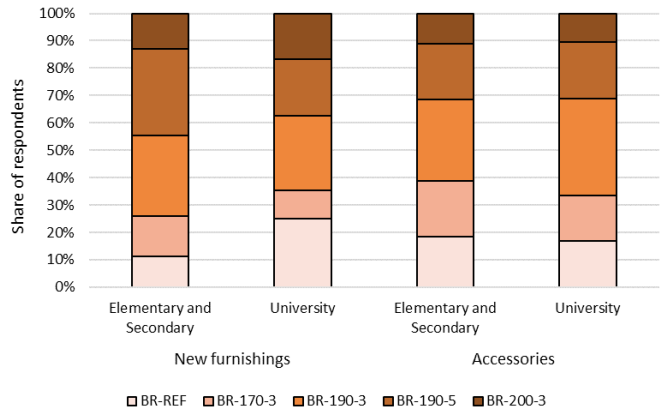

Fig. 6: New flat furnishings and purchasing a supplemental piece of furniture made of veneer - differences between the age groups.

The structure of the information on the customer preferences from the point of view of their education (maximum secondary, university and higher) is shown in Tab. 3.

Tab. 3: Proportions of the respondents according to their education willing to purchase wood furniture with a thermal treatment.

\begin{tabular}{|l|c|c|c|c|}
\hline \multirow{2}{*}{ Type of purchase } & $\begin{array}{c}\text { Type of } \\
\text { furniture }\end{array}$ & Education & $\begin{array}{c}\text { Proportion } \\
\text { of respondents }\end{array}$ & $\begin{array}{c}\text { Interval estimate } \\
\text { of the share } \\
\text { in the population }\end{array}$ \\
\hline \multirow{3}{*}{ Furnishing a new flat } & \multirow{2}{*}{ Solid wood } & $\begin{array}{c}\text { Elementary and } \\
\text { secondary }\end{array}$ & 0.981 & $0.945-1.000$ \\
\cline { 3 - 5 } & \multirow{2}{*}{ Veneer } & $\begin{array}{c}\text { University } \\
\text { Elementary and } \\
\text { secondary }\end{array}$ & 0.833 & $0.728-0.939$ \\
\cline { 3 - 5 } & University & 0.889 & $0.805-0.972$ \\
\hline \multirow{3}{*}{$\begin{array}{l}\text { Purchasing a supplemental } \\
\text { piece of furniture }\end{array}$} & \multirow{2}{*}{ Solid wood } & $\begin{array}{c}\text { Elementary and } \\
\text { secondary }\end{array}$ & 0.833 & $0.628-0.872$ \\
\cline { 3 - 5 } & \multirow{2}{*}{ Veneer } & University & 0.958 & $0.902-1.000$ \\
\cline { 3 - 5 } & & $\begin{array}{c}\text { Elementary and } \\
\text { secondary }\end{array}$ & 0.815 & $0.711-0.918$ \\
\cline { 3 - 5 } & University & 0.833 & $0.728-0.939$ \\
\hline
\end{tabular}

For the solid wood furniture for the new flat furnishings, we observed significant differences between the groups with the different education. The achieved level of significance is 0.021 . The obvious preference for darker shades among the respondents with a maximum secondary education is interesting (Fig. 7). 
With the supplemental solid wood furniture, we again observed significant differences between the groups with the different education. The achieved level of significance is 0.002 . The darker shade (BR-SW-180-3) has the largest preference in the group of respondents with a university education (Fig. 7).

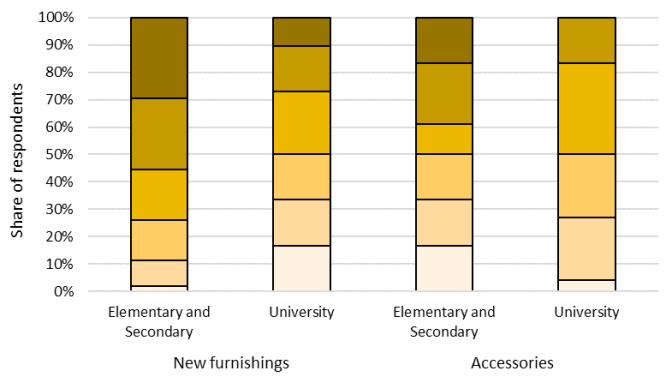

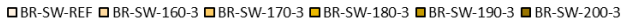

Fig. 7: Nerw flat furnishings and purchasing a solid wood furniture accessory - differences between the groups with the different education.

We did not observe significant differences between the veneer furniture for new flat furnishings between the groups with the different education. The achieved level of significance is 0.337 . The darker shade (BR-190-5) had the largest preference in the group of maximum secondary education (Fig. 8).

We also did not observe significant differences between the groups for complementary veneer furniture. The achieved level of significance is 0.972 . The medium dark shade (BR-190-3) had the largest preference in the group of respondents with a university education (Fig. 8).

We also did not observe significant differences between the groups for complementary veneer furniture. The achieved level of significance is 0.972 . The medium dark shade (BR-190-3) had the largest preference in the group of respondents with a university education (Fig. 8).

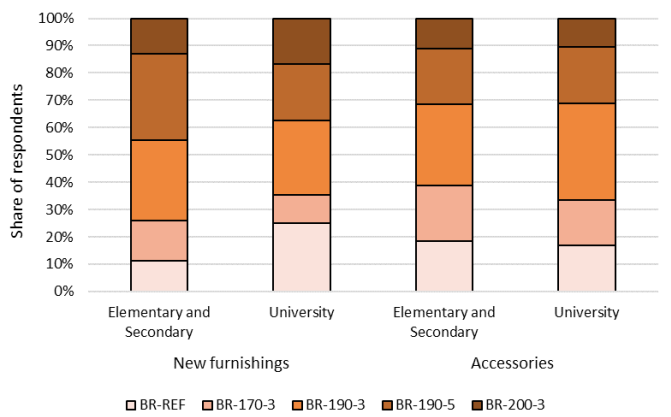

Fig. 8: New flat furnishings and purchasing furniture accessories made from veneer - differences between the groups with the different education.

The secondary analysis of the results of the questionnaire survey confirmed a higher level of attractiveness of the heat-treated samples of the solid wood and birch veneer for individual groups of customers differentiated according to their gender, age and education. The heat- 
treated samples represent darker shades. The results of the survey point to the fact that darker colours could be more preferred by the market. Similar results were obtained by Zanuttini et al. (2020). Wood colour is an important parameter for the identification, use and determination of its market value with regard to aesthetic factors (Rosu et al. 2010). In this respect, similar results were obtained by Candelier et al. (2016) because they considered the colour of the wood to be an important property for the final consumer. The reason is that the aesthetic aspect prevails for some end customers. A number of retail chains with interior furnishings offer these interior furnishingsinlightershades-anexample istheso-called "bleached oak", etc. The resultsoftheanalysis of the questionnaire survey in the Czech Republic indicate a likely change in colour preferences of potential customers towards "warmer" darker colours. However, to confirm this hypothesis, it would be appropriate to conduct a further investigation, preferably using samples of specific pieces of furniture, which would be made from raw birch wood material modified with different degrees of heat treatment.

\section{Marketing strategy}

As mentioned in the previous methodological part, a detailed SWOT analysis is a necessary prerequisite for the further decision-making and planning regarding the use of thermally treated wood technology (Tab. 4). In this case, it includes the results of our own research, an analysis of the environment and an analysis of other sources (Espinoza et al. 2015).

Tab. 4: SWOT analysis.

\begin{tabular}{|c|c|}
\hline Strengths & Weaknesses \\
\hline $\begin{array}{l}\text { - TMW looks more attractive, even luxurious, if } \\
\text { it resembles tropical woods. } \\
\text { Improved water properties; resulting in } \\
\text { greater dimensional stability. } \\
\text { - Longer material life with the possibility } \\
\text { of outdoor use. } \\
\text { - From the customers' point of view, } \\
\text { an „ecological“ colour change - without } \\
\text { the use of chemicals / paints. } \\
\text { Preservation of the possibility of material } \\
\text { processing. } \\
\text { The possibility of reusing the material } \\
\text { at the end of its economic life. }\end{array}$ & $\begin{array}{l}\text { Deterioration of some wood properties (e.g., } \\
\text { hardness). } \\
\text { - } \quad \text { Expenditure related to heat treatment. } \\
\text { - } \quad \text { existomers often do not know that TMW } \\
\text { - } \quad \text { Little used material - deeper operational } \\
\text { experience is lacking. }\end{array}$ \\
\hline Opportunities & Threats \\
\hline $\begin{array}{l}\text { - The price of TMW birch is usually lower than } \\
\text { the price of a visually similar tropical wood. } \\
\text { Reducing pressure to use tropical timber, } \\
\text { contributing to forest conservation. } \\
\text { It is still a matter of using a renewable natural } \\
\text { resource. } \\
\text { Potential use of birch wood in products with } \\
\text { higher added value - in the conditions } \\
\text { of the Czech Republic, a change in } \\
\text { the attitude of forest owners to a positive } \\
\text { view of birch and its greater representation in } \\
\text { forests. }\end{array}$ & 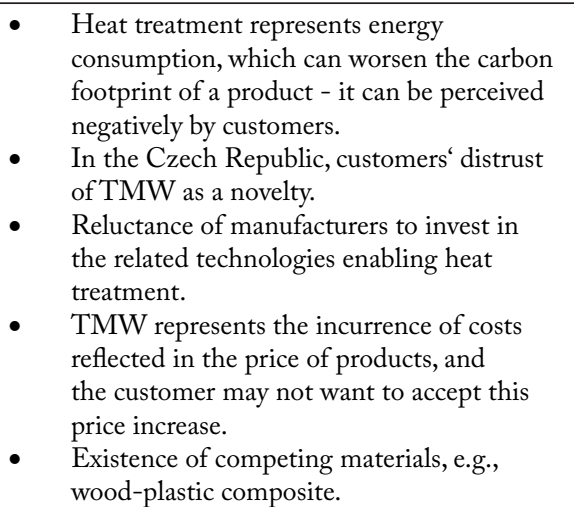 \\
\hline
\end{tabular}


The promotional strategy for TMW should consider that awareness among both the consumers and the end professional customers is very low in the Czech Republic, and those potential customers are unfamiliar with the TMW's performance and attributes. The most commonly used promotional channel for the current TMW producers is through company websites (Espinoza et al. 2015).

Customer satisfaction is one the most important factor in a successful business (Parobek et al. 2015). It will be important for the TMW industry promotion to include a mixture of stimulating demand to create awareness and increase knowledge, as well as enhance the industry image through advertising, personal selling, and sales promotion, which includes displays at trade shows (Shupe and Vlosky 2010). The systematic application of a communication mix can prepare the professional customers to successfully pursue any opportunity that arises from a supply push.

\section{CONCLUSIONS}

The results of the research point to a greater colour attractiveness of heat-treated wood and birch veneer from the point of view of the potential customers' preference. Overall, a greater preference for darker colours was confirmed compared to light colours or the reference samples without heat treatment. During the secondary analysis of the data obtained from the questionnaire survey, it was found that statistically significant differences in the preferences of potential customers occur between men and women in the case of new flat furnishing with solid wood furniture. Other significant differences were found between groups with a different education, both in the case of new flat furnishings and in the case of purchasing a supplemental piece of furniture.

These results further signal that, in relation to the final customer, heat-treated wood is a sufficiently attractive material, provided that there is a sufficiently wide product range that uses this material. TMW wood has a number of advantages: it does not contain toxic substances, it has a wide range of shades, it is a solid material with extended resistance. In addition, it makes it possible to use local sources of birch wood, which, without this treatment, would have less of an opportunity to use such wood in products with higher added value. As part of the communication strategy, it is necessary to mainly focus on professional customers, i.e., wood processors and furniture manufacturers. There is a need to increase the interest of the wood processing industry in this way to create added value to the products (veneers, lumber, etc.) and to harmonise this process view throughout the value chain. The starting point for this communication strategy is a SWOT analysis and an effective communication mix based on this strategy.

\section{ACKNOWLEDGMENT}

The research was supported by the National Agency for Agricultural Research of the Ministry of Agriculture of the Czech Republic [project No. QK1920272 - „Communication as a tool to harmonise the needs of society and the forestry sector"] and by the Grant service Forests of the Czech Republic, state enterprise [project No. 90, contract No. 3/2018]. 


\section{REFERENCES}

1. Benzaghta, M.A., Elwalda, A., Mousa, M.M., Erkan, I., Rahman, M., 2021: SWOT analysis applications: An integrative literature review. Journal of Global Business Insights 6(1): $54-72$.

2. Bhuiyan, N., 2011: A framework for successful new product development. Journal of Industrial Engineering and Management 4(4): 746-770.

3. Borůvka, V., Dudík, R., Zeidler, A., Holeček, T., 2019: Influence of site conditions and quality of birch wood on its properties and utilization after heat treatment. Part I. Elastic and strength properties, relationship to water and dimensional stability. Forests 10(2): 189.

4. de Cademartori, P.H.G., Mattos, B.D., Missio, A.L., Gatto, D.A., 2014: Colour responses of two fast-growing hardwoods to two-step steam-heat treatments. Materials Research 17(2): 487-493.

5. Candelier, K., Thevenon, M.F., Petrissans, A., Dumarcay, S., Gerardin, P., Petrissans, M., 2016: Control of wood thermal treatment and its effects on decay resistance: a review. Annals of Forest Science 73: 571-583.

6. Choe, W.J., Ji, I., 2019: The performance of supply-push versus demand-pull technology transfer and the role of technology marketing strategies: The case of a Korean Public Research Institute. Sustainability 11(7): 2005.

7. Cooper, R.G., 2019: The drivers of success in new-product development. Industrial Marketing Management 76: 36-47.

8. Dudík, R., Šišák, L., Riedl, M., 2018: Regeneration of declining spruce stands in the Czech Republic - economic view of an alternative species composition. In: Book of abstracts "Sustainable forest management for the future - the role of managerial economics and accounting”. Pp 25-26, Croatia.

9. Dudík, R., Borůvka, V., Zeidler, A., Holeček, T., Riedl, M., 2020: Influence of site conditions and quality of birch wood on its properties and utilization after heat-treatment. Part II. Surface properties and marketing evaluation of the effect of the treatment on final usage of such wood. Forests 11(5): 556.

10. Espinoza, O., Buehlmann, U., Laguarda-Mallo, M.F. 2015: Thermally modified wood: Marketing strategies of US producers. BioResources 10(4): 6942-6952.

11. Gamache, S.L., Espinoza, O., 2017: Marketing strategy recommendations for the U.S. thermally modified wood industry. University of Minnesota, $54 \mathrm{pp}$.

12. Jirouš-Rajković, V., Miklečić, J., 2019: Heat-treated wood as a substrate for coatings, weathering of heat-treated wood, and coating performance on heat-treated wood - review article. Advances in Materials Science and Engineering, Article ID 8621486: 9.

13. Kaputa, V., Šupín, M., 2010: Consumer preferences for furniture. In: Wood processing and furniture manufacturing: Present conditions, opportunities and new challenges (ed. Paluš, H.). Pp 81-90, WoodEMA, i.a. Zagreb.

14. Lane, J.P., 1999: Understanding technology transfer. Assistive Technology 11(1): 5-19.

15. Loučanová, E., Paluš, H., Dzian, M., 2017: A course of innovations in wood processing industry within the forestry-wood chain in Slovakia: a Q methodology study to identify future orientation in the sector. Forests 8(6): 210.

16. Militz, H., Lande, S., 2009: Challenges in wood modification technology on the way to practical applications. Wood Material Science and Engineering 4(1-2): 23-29.

17. Palátová, P., 2019: Value added in sawmilling industry in the Czech Republic. Central European Forestry Journal 65(1): 60-65. 
18. Parobek, J., Paluš, H., 2008: Modelling of wood and wood products flow in the Slovak Republic. In: COST conference on a European wood processing strategy: Future resources matching products and innovations. Pp 93-99, Ghent University, Belgium.

19. Parobek, J., Loučanová, E., Nosálová, M., Šupín, M., Štofková, K.R., 2015: Customer window quadrant as a tool for tracking customer satisfaction on the furniture market. In International Scientific Conference: Business Economics and Management (ed. Sujova, A., Krajcirova, L.). Pp 493-499, Book Series: Procedia Economics and Finance.

20. Rosu, D., Teaca, C.A., Bodirlau, R., Rosu, L., 2010: FTIR and color change of the modified wood as a result of artificial light irradiation. Journal of Photochemistry and Photobiology B-Biology 99(3): 144-149.

21. Dos Santos, D.V.B., De Moura, L.F., Brito, J.O., 2014: Effect of heat treatment on color, weight loss, specific gravity and equilibrium moisture content of two low market valued tropical woods. Wood Research 59(2): 253-264.

22. Sedlar, T., Sinković, T., Perić, I., Jarc, A., Stojnić, S., Šefc, B., 2019: Hardness of thermally modified beech wood and hornbeam wood. Sumarski list 143(9-10): 425-433.

23. Ulrich, K.T., Eppinger, S.D., 2007: Product design and development. 4th ed., McGrawHill, New York, 384 p.

24. Shupe, T.F., Vlosky, R.P., 2010: Why and how to market wood products. Louisiana Forest Products Development Center, 10 pp.

25. Wonnacot, T.H., Wonnacot, R.J., 1977: Introductory statistics, 3rd ed., John Wiley, New York, 650 pp.

26. Zanuttini, R., Castro, G., Cremonini, C., Negro, F., Palanti, S., 2020: Thermo-vacuum treatment of poplar (Populus spp.) plywood. Holzforschung 74(1): 60-67.

Roman Dudík, Marcel Riedl

Czech University Of Life Sciences Prague

Faculty Of Forestry And Wood Sciences

Department Of Forestry And Wood Economics

KamÝcká i29, i65 oo Praha 6 - Suchdol

Czech Republic

Vlastimil Borůvka*, Tomáš Holeček

Czech University Of Life Sciences Prague

Faculty Of Forestry And Wood Sciences

Department Of Wood Processing And Biomaterials

Department Of Forest Biomaterials Engineering

Kamýcká i29, i65 oo Praha 6 - Suchdol

Czech Republic

*Corresponding author: boruvkav@fld.czu.cz 
